\title{
A CADEIA PRODUTIVA DO LEITE E O COOPERATIVISMO NOS ASSENTAMENTOS DE REFORMA AGRÁRIA DA FRONTEIRA SUL DO RIO GRANDE DO SUL
}

\section{RESUMO}

Este estudo analisa o potencial socioeconômico da cadeia produtiva do leite em um território rural gaúcho, localizado na fronteira do Brasil com o Uruguai, com 145 assentamentos, mais de 10 mil famílias e diversas cooperativas de produtores de leite. Buscaram-se subsídios empíricos que pudessem servir de base para a elaboração de uma política de desenvolvimento territorial rural, baseado em um modelo teórico-metodológico que considere as diferentes dinâmicas territoriais, o capital social presente, as oportunidades externas oferecidas pelo mercado e as potencialidades locais. Identificaram-se alguns gargalos e possíveis soluções socioeconômicas, tecnológicas e mercadológicas determinantes do desenvolvimento da produção leiteira, das cooperativas e dos assentamentos da região. Espera-se que a organização interna da produção e o desenvolvimento do cooperativismo e da cadeia produtiva do leite na região possam ser importantes instrumentos de desenvolvimento socioeconômico dos assentamentos e da região. Acredita-se que seja possível o desenvolvimento sustentável desse território rural através da formação e da consolidação de um sistema produtivo agroalimentar localizado na região, como instrumento de coordenação e mediação da dinâmica socioeconômica de desenvolvimento do território.

Palavras-chave: Reforma agrária. Instituições. Desenvolvimento territorial rural. Cadeia produtiva do leite.

\section{ABSTRACT}

This study examines the socio-economic potential of the milk productive chain in a rural

\footnotetext{
${ }^{1}$ Economista, Mestre em Desenvolvimento Regional. Professora da Faculdade de Administração das Faculdades Integradas de Taquara (Faccat)/RS e doutoranda em Desenvolvimento Regional na Universidade de Santa Cruz do Sul (Unisc).dilanib@faccat.br

2 Engenheiro Agrônomo, Mestre em Economia Rural e Doutor em Desenvolvimento Rural. Professor do Departamento de Economia da Unisc/RS e do Programa de Pós-Graduação em Desenvolvimento Regional da Faccat/RS. jmoraes12@gmail.com
} 
territory of the Rio Grande do Sul, located on the border between Brazil and Uruguay, with 145 settlements, more than 10.000 families and several cooperatives of milk producers. We tried to subsidies that could serve as empirical basis for the elaboration of a territorial rural development policy, based on a theoretical-methodological model that considers the different territorial dynamics, the present capital, external opportunities offered by the market, the local potential. Identified the main bottlenecks and possible solutions socioeconomic, technological and market determinants of the development of milk production cooperatives and settlements in the region. It is expected that the internal organization of production and development of cooperatives and the milk productive chain in the region can be important tools for socio-economic development of settlements and the region. It is believed that sustainable development is possible this rural area through the formation and consolidation of a located agrifood system, as instrument of coordination and mediation of dynamic socioeconomic development planning.

Keywords: Agrarian reform. Rural development. Territorial development. Milk productive chain.

\section{INTRODUÇÃO}

Na busca por novos modelos de atuação governamental e de formulação e gestão de políticas públicas para o desenvolvimento territorial, a construção de um sistema produtivo local autônomo, mais integrado às redes globais, que utiliza de forma sustentável os seus recursos locais, pode ser parte de uma estratégia de desenvolvimento dos territórios rurais. Na perspectiva territorial, os atores fundamentais do desenvolvimento são o Estado, os movimentos populares, as associações e as cooperativas e os demais agentes econômicos locais. Dessa forma, espera-se que aconteça o desenvolvimento sustentável (socioeconômico e ambiental) do território e a ampliação da democracia local nas decisões econômicas (MORAES, 2008). Nesse processo, devem ser implementados programas que estimulem o aumento de empregos, a eliminação da fome, a redução da pobreza e a reinserção social de segmentos marginalizados e/ou de trabalhadores pouco qualificados, como é o caso de grande parte dos assentados da reforma agrária.

No debate teórico brasileiro recente sobre desenvolvimento dos territórios rurais, já não restam dúvidas sobre a importância do papel da produção familiar e do Estado nas políticas de desenvolvimento territorial. Ao mesmo tempo, o reconhecimento da importância da agricultura familiar para o desenvolvimento socioeconômico de assentamentos é apontado como uma das justificativas estratégicas para a reforma agrária, sendo esta a oportunidade para pequenos agricultores, arrendatários, minifundistas e trabalhadores rurais sem-terra terem acesso à propriedade da terra, reproduzindo-se na condição de agricultores familiares.

A reforma agrária tem sido uma forma de acesso direto à terra e também de inserção na vida econômica, qualificando produtores e diversificando a produção. Essa diversificação tem sido um dos fatores de mudança na vida das famílias rurais e urbanas que passam a fazer parte dos mercados, aumentando a oferta de alimentos e a deman- 
da por insumos agropecuários, bens de consumo duráveis, máquinas e implementos agrícolas, passando a serem novos consumidores de produtos no comércio local. Esses assentamentos podem ser considerados uma alternativa para o trabalho agrícola e não agrícola e solução para o problema de moradia. No entanto, os assentamentos de reforma agrária realizados nos últimos 20 anos no Brasil nem sempre têm implicado melhorias das condições de vida e de renda das famílias rurais assentadas, quando não são criados os instrumentos para que essas famílias possam se desenvolver e contribuir para o desenvolvimento territorial rural (CARVALHO, 2009).

Um estudo coordenado por Guanziroli (1998), realizado em conjunto com técnicos do Departamento de Estudos Socioeconômicos Rurais (DESER), resultante de um projeto de cooperação técnica FAO/INCRA (1998), identificou diversos fatores potencializadores e restritivos do desenvolvimento de projetos de assentamentos de reforma agrária no Brasil. O estudo constatou que a disponibilidade de crédito, a organização e o uso do quadro natural, o entorno produtivo e/ou consumidor, a organização da produção e a assistência técnica são os principais fatores que potencializam o sucesso dos projetos de assentamentos. Além desses, apontaram também a organização política e o apoio institucional na melhoria da infraestrutura produtiva e de serviços atuando tanto para melhorar as condições sociais dos assentados como para potencializar os sistemas produtivos. Os principais fatores limitantes ao desenvolvimento dos assentamentos foram a situação desfavorável do quadro natural, a precariedade das estradas internas e dos acessos, a falta de assistência técnica e a inexistência de organizações produtivas e políticas entre os assentados, o baixo índice de acesso ao crédito e a falta de infraestrutura básica, que afetam negativamente a renda e a qualidade de vida dos assentados.

De maneira geral, ao lado do nível de organização da produção, esses fatores têm um importante papel no desenvolvimento dos assentamentos, reduzindo os custos, potencializando o uso dos recursos naturais, gerando sistemas produtivos mais rentáveis e ampliando as alternativas econômicas dos assentamentos. Assim, o melhoramento das condições socioeconômicas dos assentamentos poderia ser viabilizado pela maior capacidade de interlocução com os órgãos públicos, pela organização política dos próprios assentados e pela ação direta do Estado na viabilização da infraestrutura básica.

Este estudo é parte de uma busca estratégica de subsídios para a elaboração de políticas e de projetos de desenvolvimento rural e territorial para as diferentes dinâmicas territoriais, que permitem uma reflexão teórica em torno da importância das instituições e da participação dos atores locais. Mais especificamente, o estudo procura identificar a contribuição potencial da produção leiteira e das cooperativas de produtores de leite dos assentamentos de reforma agrária para o desenvolvimento local das regiões administrativas (Coredes) Sul, Campanha e parte da Fronteira-Oeste do Rio Grande do Sul. Para isso, o trabalho avaliou a situação atual e potencial da produção leiteira e as suas relações com as dinâmicas socioeconômicas e ambientais de desenvolvimento desse território, o qual tem um eixo central passando pelos municípios de Herval, Pedras Altas, Candiota, Hulha Negra, Canguçu, Piratini e Santana do Livramento.

O objetivo principal deste estudo foi analisar o potencial de desenvolvimento da cadeia produtiva do leite em um território rural com quase cento e cinquenta assentamentos de reforma agrária, nas regiões Sul, Campanha e parte da Fronteira-Oeste do 
Rio Grande do Sul, como instrumento de política pública visando à inclusão social e à redução da pobreza de cerca de dez mil famílias assentadas nesse território. Espera-se, assim, desde que com a participação do Estado e da sociedade civil organizada (movimentos sociais, cooperativas, associações), ou seja, o capital social do território, que esse instrumento possa contribuir para o desenvolvimento sustentável desse território.

Para obtenção das informações principais, foi efetuado um levantamento de dados primários através de entrevistas presenciais utilizando-se questões abertas, com dirigentes e técnicos de quase uma dezena de cooperativas e/ou associações de agricultores familiares assentados nos municípios de Santana do Livramento, Candiota, Herval, Hulha Negra, Pedras Altas, Piratini e Canguçu.

Na análise do perfil socioeconômico da produção leiteira nos assentamentos da região, foram utilizados também dados secundários de pesquisa bibliográfica e digital nas fontes relacionadas. Esse levantamento levou em consideração os principais antecedentes, estudos e pesquisas disponíveis, com enfoque sobre os diagnósticos socioeconômicos e de viabilidade de implantação de alternativas produtivas para a região de abrangência dos assentamentos e das cooperativas de assentados produtores de leite.

Espera-se que os resultados deste trabalho possam ser úteis para medidas e políticas de desenvolvimento territorial, que aproveitem o potencial endógeno dos territórios rurais e a oportunidade de mercado oferecida pela cadeia produtiva do leite. Esta se apresenta como uma atividade de grande potencial dinamizador e transformador da realidade socioeconômica em escala regional, através da geração de renda e de ocupação para a população desse território.

A seguir, apresentam-se algumas considerações teóricas sobre a perspectiva territorial do desenvolvimento, as dinâmicas socioeconômicas do desenvolvimento dos territórios rurais e capital social.

\section{A PERSPECTIVA TERRITORIAL DO DESENVOLVIMENTO RURAL}

As novas abordagens da geografia econômica e da sociologia econômica, em termos de definição do território, têm uma perspectiva muito dinâmica, o que parece relevante, já que os sistemas estão em constante evolução. O território é resultante da relação da sociedade com o espaço, quando a esse se incorpora a sociedade com suas relações econômicas e de produção. Para que se tenha um território, é necessário que a sociedade ou grupos sociais apropriem-se do espaço físico, ampliem e utilizem as inovações tecnológicas e que exista um sentimento de pertencimento ou a identificação da sociedade com o seu território (MORAES, 2008).

A dinâmica territorial e institucional associa o território aos atributos da diferenciação e da aglomeração (ou densidades), os quais, de acordo com Reis (2006), justificam a existência do território. Essa dinâmica está relacionada com lógicas de proximidade, as quais dão origem às aglomerações, que servem de base para as estruturas institucionais. Além disso, o desenvolvimento territorial depende da capacidade de cada território para mesclar e aproveitar, ao mesmo tempo, as suas potencialidades locais e as oportunidades externas. 
Atualmente, define-se espaço apenas como um "campo de existência", que não desaparece quando é criado o território e que tem sua forma, limites e malha territorial determinados pelas manifestações das relações de poder, com origem na população, no território e nos seus diversos recursos (RAFFESTIN, 1993). A população está na origem do poder porque é de onde vem o potencial de transformação, ou seja, é o elemento dinâmico de onde vem a ação. Enquanto o espaço serve de cenário, o território é a cena do poder e o lugar onde acontecem todas as relações.

Outras considerações em relação ao território foram feitas por Boisier (1997), para quem o território é um recorte da superfície terrestre que se apresenta como um conjunto de três características: um território "natural", sem considerar a presença humana (o que está mais para uma noção de espaço); um território "equipado", onde se verifica a presença humana através da instalação de fluxos e de atividades produtivas e extrativas; e o território "organizado", quando aparecem atividades humanas e fluxos mais complexos e verifica-se a "existência de uma comunidade que se reconhece e que tem como autorreferência primária o próprio território", ou seja, tem uma identidade com este. Essa última definição, o de território "organizado", que passa a ser sujeito "de intervenções promotoras do desenvolvimento" e tem uma estrutura político-administrativa, é a que está mais próxima do que se entende atualmente como a mais adequada para uso nas abordagens territoriais do desenvolvimento rural.

Schejtman e Berdegué (2003) descrevem, de forma sistemática, a evolução do enfoque territorial e os conceitos e critérios operativos da abordagem centrada no Desenvolvimento Territorial Rural (DTR). Esses autores definem DTR como um processo de transformação produtiva e institucional em um determinado espaço rural com a finalidade de reduzir a pobreza local. Além da preocupação com a pobreza rural, reforçam o propósito de a produção se articular, de forma competitiva e sustentável, com a economia interna do território e com mercados externos dinâmicos. Além disso, segundo eles, o desenvolvimento institucional tem o propósito de estimular e facilitar a interação e a articulação dos atores locais entre si e com os agentes externos relevantes.

Portanto, é possível afirmar que todo modelo de desenvolvimento que tenha a finalidade de impulsionar o desenvolvimento humano e elevar a qualidade de vida da população de um determinado território rural terá de levar em conta as realidades, diversidades e potencialidades locais desses territórios, de suas aglomerações produtivas e de suas articulações externas. Conhecer essas realidades é vital para a eficácia de políticas e instrumentos de desenvolvimento mais ajustados aos perfis territoriais, que tenham como alvo a redução da pobreza, o fomento de atividades produtivas e a modernização tecnológica e empresarial.

Então, quando se utiliza o termo dinâmica territorial rural, entende-se como sendo o ambiente onde é possível a utilização das potencialidades próprias do território rural e, ao mesmo tempo, o aproveitamento das oportunidades externas, constituindo-se uma dinâmica socioeconômica local diferenciada de desenvolvimento rural, instrumentalizada e mediada através de seus SIALs (CORREA, 2004; SABOURIN, 2002). As ligações entre o global e o local dentro dos territórios e as articulações entre alguns referenciais teóricos institucionalistas com a abordagem territorial do desenvolvimento são realiza- 
das utilizando-se os pressupostos teóricos que sustentam a "imersão" ou "enraizamento" (embeddedness) da economia de mercado no sistema social, propostos por Polanyi (2000). Esses são os principais subsídios teóricos de sustentação dessa abordagem de análise do desenvolvimento socioeconômico e ambiental dos territórios rurais.

\section{DINÂMICAS DE DESENVOLVIMENTO DOS TERRITÓRIOS RURAIS}

Após a Segunda Guerra Mundial, as áreas rurais dos países mais desenvolvidos foram estruturadas com base em um modelo de desenvolvimento da agricultura que ficou conhecido como modernização agrícola. Esse modelo se caracterizou pela integração e pela funcionalidade da agricultura ao modo de desenvolvimento fordista do sistema econômico capitalista, no qual o rural era considerado sinônimo de agrícola, por isso podendo ser denominado de rural-agrícola. No Brasil, a modernização da agricultura - na qual o rural-agrícola cumpriu o seu papel funcional de fornecimento de trabalhadores, alimentos, matérias-primas, divisas e outros recursos para o setor urbano-industrial - provocou um grande fluxo de população, atraída pelas cidades e expulsa pela pobreza e pelo isolamento rural. Esse processo de migração rural-urbana gerou uma favelização dos grandes centros urbanos, uma vez que o setor industrial-urbano não teve capacidade para absorver todo o excedente de população rural (MORAES, 2008).

No debate brasileiro, dos últimos anos, em torno do desenvolvimento rural, da mesma forma que já se fazia na Europa desde o final da década de 1970, verifica-se uma mudança de visão nas novas abordagens utilizadas para compreender o papel do rural no desenvolvimento regional do país.

De acordo com Navarro (2001), embora a definição do que seja exatamente desenvolvimento rural tenha variado ao longo do tempo, normalmente nenhuma das propostas conceituais deixa de destacar a melhoria do bem-estar das populações rurais e locais como objetivo final do desenvolvimento rural. O conceito de desenvolvimento rural alterou-se ao longo do tempo, influenciado por diversas conjunturas e, principalmente, pelos novos condicionantes que o desenvolvimento macroeconômico e a vida social, gradualmente, impõem às famílias e às atividades rurais. No Brasil, desde os anos noventa, o próprio significado de rural tem sido objeto de debate entre pesquisadores e, em consequência disso, os seus conceitos tradicionais vêm sendo repensados. $\mathrm{O}$ abandono da identificação do rural como sinônimo de agrícola e a pouca utilidade da dicotomia rural-urbano para as análises do desenvolvimento já é fruto desse debate.

Para Abramovay (2000), não existe qualquer razão para que o conceito de meio rural seja associado à ideia de um declínio ao longo do tempo, mesmo considerando uma real e significativa redução histórica do peso da produção agrícola na maioria das economias nacionais. As dinâmicas de algumas regiões rurais, principalmente em função dos menores custos de reprodução da força de trabalho e da proximidade resultante da expansão da infraestrutura de transportes e comunicações, demonstram que a ruralidade não impede a geração de empregos e que, muitas vezes, também a baixa densidade populacional e as distâncias não são obstáculos ao desenvolvimento.

Essas perspectivas vêm substituindo a visão tradicional, a qual se apoia na dicoto- 
mia rural-urbana, que ainda relaciona o rural com atraso e como sinônimo de agrícola e, por outro lado, o urbano com moderno, industrial e serviços. A nova perspectiva sobre o mundo rural se apoia em argumentos que abrem a possibilidade de o território rural oferecer alternativas de emprego e renda e diversas outras formas de melhoria na qualidade de vida da sua população. Entretanto, para oferecer isso, o território rural deve utilizar o seu potencial local e aproveitar as suas características históricas e culturais particulares e estar socioeconomicamente integrado ao seu entorno e ao exterior. Esses são os contornos que poderão contribuir para o desenvolvimento local dos territórios rurais (MORAES, 2008).

Quando se agregam as estruturas de governança, que direcionam a dinâmica de uma aglomeração produtiva agroalimentar regional, esta passa a formar um sistema produtivo agroalimentar local. A diversidade e a complexidade dessas aglomerações produtivas e os conflitos internos entre os agentes estimulam a criação de instâncias de negociação e organização dos agentes produtivos, na forma de associações ou cooperativas. Um sistema produtivo agroalimentar local só existe de verdade quando são constituídas as instituições regionais responsáveis pela governança e pela administração da solidariedade sistêmica, ou seja, quando há capital social (MORAES, 2008).

Nas próximas seções, descreve-se uma síntese panorâmica da região de abrangência do território onde estão localizados os assentamentos e as cooperativas de produtores de leite. Em seguida, apresentam-se algumas considerações sobre a importância da produção leiteira nos assentamentos para o desenvolvimento socioeconômico do território.

\section{A REGIÃO DE ABRANGÊNCIA DO ESTUDO: O TERRITÓRIO FORMADO PELOS MUNICÍPIOS-SEDE DOS ASSENTAMENTOS DA REGIÃO}

De acordo com Leite, Heredia e Medeiros (2004), os movimentos e conflitos sociais originados a partir da questão agrária brasileira, mais concentrados em determinadas regiões, resultaram em desapropriações e na criação de vários assentamentos em um mesmo município ou em municípios próximos, com sistemas produtivos baseados em pecuária extensiva, característicos das grandes propriedades em crise. Esse é o caso da região da fronteira com o Uruguai, no sul do estado do Rio Grande do Sul, nos municípios de Herval, Piratini, Canguçu, Candiota, Hulha Negra e Santana do Livramento, onde se formou uma grande "mancha" de reforma agrária, com 145 assentamentos de reforma agrária e mais de dez mil famílias assentadas, vindas de outras regiões do estado, criando uma nova e ainda não muito clara dinâmica socioeconômica na região.

Além da redistribuição fundiária e da viabilização do acesso à terra a uma população de trabalhadores rurais, originários, predominantemente, de outras regiões do estado, não houve alteração radical do quadro de concentração da terra ou alterações na estrutura agrária da região como um todo. Esses assentamentos se tornaram espaços locais de referência para políticas públicas e ponto de partida para novas demandas, as quais, além da afirmação de novas identidades, interesses e atores sociais, também provocam mudanças no cenário político local. Com isso, segundo Moraes (2008), há um 
redesenho estrutural da região, uma modificação da paisagem e das relações de poder local, levando à formação de novas aglomerações populacionais e a mudanças do padrão produtivo dos municípios e das regiões.

Entre as mudanças locais, resultantes da criação dos assentamentos, estão a maior diversidade e quantidade de bens ofertados no mercado, a dinamização do comércio local, em consequência do aumento potencial da capacidade de consumo e do acesso ao crédito para produção pelos assentados e das inovações no beneficiamento de produtos e nas formas de comercialização. Por outro lado, constata-se também uma insuficiente intervenção do Estado no processo de transformação, principalmente quando se verifica a continuidade da precariedade dos serviços de saúde, educação, infraestrutura e acesso à assistência técnica.

A região de abrangência do estudo é formada pelas microrregiões (IBGE, 2011) Jaguarão, Pelotas, Serras de Sudeste, Campanha Central e Campanha Meridional, com um total de trinta municípios. Esse território está localizado no sul do Rio Grande do Sul, na fronteira com o Uruguai, com uma área de quase 4,8 milhões de hectares e aproximadamente um milhão de habitantes, dois terços destes concentrados em Pelotas. Nesse território, ligado diretamente à presença histórica do gado bovino, principal atrativo para a sua ocupação nos séculos XVIII e XIX, predomina uma densidade demográfica muito baixa, estabelecimentos rurais médios e grandes e uma economia baseada, historicamente, na pecuária extensiva de bovinos de corte e na ovinocultura. Atualmente, a região tem sua matriz produtiva agroindustrial baseada na produção agropecuária, basicamente a tradicional pecuária de corte e a produção de leite e, de forma bastante localizada, a de uva e de alguns grãos (arroz, soja e trigo), enquanto ocorre uma expansão acelerada da área com eucalipto para a produção de celulose (IBGE, 2011; FEE, 2011).

No entanto, a arquitetura do estudo foi elaborada especificamente para apenas doze municípios, dispersos nessas regiões, que inicialmente poderiam ser os beneficiários diretos dos resultados do estudo: são os municípios-sede dos assentamentos da região. Esses municípios, juntos, ocupam uma área de aproximadamente 2,8 milhões de hectares, têm uma população de quase 300 mil habitantes e abrigam cento e quarenta e cinco assentamentos e mais de dez mil famílias assentadas, grande parte delas organizadas em cooperativas ou associações para produzirem, principalmente, leite. Em 2008, o PIB total desses municípios-sede da região era de $\mathrm{R} \$ 2,87$ bilhões, observando-se que a soma total do PIB de 75\% deles não ultrapassava R\$ 1,16 bilhão (Tabela 1).

Esses municípios produzem em torno de 200 mil litros de leite resfriado/dia, e quase a metade dessa produção é gerada pelas cooperativas e associações de assentados, que é destinada à Cosulat, a mais importante cooperativa agroindustrial da região. Essa cooperativa tem potencial para processar até um milhão de litros por dia, no entanto sua capacidade ociosa atual é de aproximadamente $50 \%$, por falta de matéria-prima. 


\begin{tabular}{l|r|r|r|r|r|rr}
\hline \multicolumn{1}{c|}{ Habitantes } & \multicolumn{2}{c|}{$\%$} & \multicolumn{1}{c|}{ PIB } & \multicolumn{2}{r}{ Assentam. } \\
\hline \multicolumn{1}{c}{ Município } & \multicolumn{1}{c}{ Rural } & \multicolumn{1}{c}{ Urbana } & \multicolumn{1}{c}{ Total } & \multicolumn{1}{c}{ Rural } & Urbana & em R\$1.000 & unidades \\
\hline Aceguá & 3.141 & 1.145 & 4.286 & 73,3 & 26,7 & 76.502 & 6 \\
Arroio Grande & 2.309 & 16.370 & 18.679 & 12,4 & 87,6 & 209.872 & 4 \\
Candiota & 5.467 & 2.832 & 8.299 & 65,9 & 34,1 & 230.416 & 23 \\
Canguçu & 33.193 & 20.909 & 54.102 & 61,4 & 38,6 & 463.304 & 16 \\
Dom Pedrito & 3.010 & 35.896 & 38.906 & 7,7 & 92,3 & 465.711 & 3 \\
Encruzilhada do Sul & 7.292 & 17.187 & 24.479 & 29,8 & 70,2 & 187.126 & 6 \\
Herval & 2.225 & 4.781 & 7.006 & 31,8 & 68,2 & 53.688 & 10 \\
Hulha Negra & 3.210 & 2.877 & 6.087 & 52,7 & 47,3 & 81.918 & 25 \\
Pedras Altas & 1.655 & 948 & 2.603 & 63,6 & 36,4 & 37.066 & 5 \\
Pinheiro Machado & 2.982 & 10.112 & 13.094 & 22,8 & 77,2 & 124.532 & 7 \\
Piratini & 7.878 & 12.595 & 20.473 & 38,5 & 61,5 & 158.465 & 15 \\
S. do Livramento & 7.241 & 77.911 & 85.152 & 8,5 & 91,5 & 782.185 & 25 \\
\hline TOTAL & $\mathbf{7 9 . 6 0 3}$ & $\mathbf{2 0 3 . 5 6 3}$ & $\mathbf{2 8 3 . 1 6 6}$ & $\mathbf{2 8 , 0}$ & $\mathbf{7 2 , 0}$ & $\mathbf{2 . 8 7 0 . 7 8 5}$ & $\mathbf{1 4 5}$ \\
\hline
\end{tabular}

Tabela 1: População dos Municípios-Sede dos Assentamentos da Região - em 2008

Fonte: FEE (2011).

A produção leiteira e as cooperativas de produtores de leite representam, para a região, um dos principais caminhos para a geração de renda e emprego. Por isso, existe a necessidade de fortalecimento desse setor, no sentido de agregar valor ao produto leite, investindo-se tanto na própria produção leiteira como na de derivados, como queijo, iogurte e demais produtos, para que seja possível ampliar o horizonte de produção. Paralelamente à produção de leite, tem-se a possibilidade de investimentos na produção de rações para os rebanhos, o que também se revela uma atividade de interesse. A produção leiteira mostrou-se, em uma pesquisa de campo preliminar, como uma das alternativas mais consistentes para os municípios-sede das cooperativas. No entanto, é importante trabalhar questões como a qualidade do rebanho e das pastagens e a produtividade leiteira.

Portanto, na região, revela-se um potencial para a produção leiteira e um espaço para diferentes formas de estruturação de parcerias entre as cooperativas dos assentamentos. Com isso, fortaleceria a geração de postos de trabalho para as famílias locais,contribuindo para a redução das desigualdades regionais e para a promoção do desenvolvimento territorial.

A regulação e a globalização ainda se apresentam com características setoriais. Os mercados do arroz e da carne bovina historicamente são considerados como determinantes das dinâmicas de desenvolvimento econômico de grande parte do território que abriga as cooperativas analisadas no presente trabalho. Recentemente, o leite começou a mudar a história do cooperativismo e da economia agrícola da região da Campanha e da Fronteira-Oeste, por isso, a seguir, descreve-se um panorama mais detalhado do mercado do leite e seus derivados. 


\section{OPORTUNIDADE DE MERCADO PARA O LEITE PRODUZIDO NOS ASSENTAMENTOS}

O mercado internacional de produtos lácteos é um mercado relativamente pequeno, representa menos de $5 \%$ da produção mundial, de aproximadamente 800 biIhões de litros, porque o leite ainda tem como uma das suas principais características a proximidade, tanto geográfica como em termos de crescimento, entre a produção e o consumo. Grande parte da produção mundial de leite destinada ao mercado internacional tem um custo que a inviabiliza (mantendo-se ainda graças aos subsídios) se os preços de venda do produto permanecerem em patamares abaixo de US\$ 0,25/ $\mathrm{kg}$. Portanto, nos próximos anos, ou os preços tenderão a se elevar um pouco, ou haverá uma redução na oferta para esse mercado, com a confirmação da extinção, a partir de 2014, dos subsídios da União Europeia às suas exportações de leite. Acredita-se que um possível aumento nos preços do leite no mercado externo provocará um aumento na produção e na exportação (inclusive com a entrada no mercado daquela produção com custos mais altos) e uma pequena redução no consumo nos países importadores, derivada do aumento dos preços e da sua elasticidade-preço (CEPEA-ESALQ/USP, 2011).

As exportações brasileiras de produtos lácteos, destacadamente o leite em pó, vêm aumentando nos últimos anos, sustentadas pelo crescimento da demanda mundial em ritmo mais acelerado do que a oferta internacional. O Brasil tem condições de ampliar a sua participação nesse mercado e atender ao mercado interno, pois a exportação brasileira de leite ainda representa menos de $1 \%$ da produção nacional. Esse crescimento da demanda externa estimulou o produtor interno a aumentar o seu plantel de vacas leiteiras, e aponta-se para uma consolidação do Brasil como um dos grandes exportadores mundiais de produtos derivados do leite, ao lado de Nova Zelândia, Austrália e União Europeia (CEPEA-ESALQ/USP, 2011).

Nos últimos anos, os exportadores brasileiros vêm se preparando para explorar esse mercado, com as indústrias de leite em pó (privadas e cooperativas) fazendo grandes investimentos em novas plantas produtivas e ampliando as suas áreas de abrangência e de coleta de leite, agora favorecidas pela conjuntura favorável para as exportações do produto.

A produção brasileira de leite vem crescendo nos últimos anos, principalmente a partir de 2006, estimulada pela alta dos preços. A grande vantagem do Brasil é que ainda podemos aumentar significativamente a produção sem a necessidade de aumentar a área ocupada ou o tamanho do rebanho leiteiro. Certamente, para isso, será necessário investir no melhoramento genético dos rebanhos e, principalmente, na qualidade da alimentação e do manejo, pois enquanto a produtividade média brasileira é de 1,7 toneladas/vaca/ano, a produtividade média nos Estados Unidos é superior a 9 toneladas/vaca/ano (CEPEA-ESALQ/USP, 2011).

A tendência do setor leiteiro é que ocorra uma acelerada concentração na indústria de laticínios e que o cooperativismo, como já acontece em diversos países, passe a ter um papel mais importante nesse processo. Isso porque o controle da produção pelos produtores somente será possível com a presença de um cooperativismo forte, principalmente na etapa de captação do leite, pois essa representa um custo bastante significativo. Complementarmente às demais medidas, o efetivo dinamismo da atividade 
produtiva do leite se dará com base, entre outros aspectos, na melhoria do sistema de captação, estudando-se rotas, volumes, frequências e custos de transporte.

Um dos fatores que contribuiu para a entrada do Brasil no mercado mundial, nos últimos anos, foram os problemas climáticos que atingiram a Nova Zelândia e a Austrália, grandes produtores e exportadores mundiais, ao lado da redução de subsídios nos países europeus. Com isso, houve uma retração na oferta, e a cotação do leite em pó nesse mercado cresceu mais do que o dobro do que vinha sendo praticado até então, segundo Cepea/Esalq/USP (2011), ultrapassando US\$ 5.000/tonelada de leite em pó.

Além de buscar a redução dos custos, é importante também ter como objetivo o aumento da produção, porque uma renda muito pequena para o produtor de leite limita os investimentos na atividade. Esse é um dos principais motivos para o fortalecimento das cooperativas de laticínios, integradas em redes ou em centrais, como já acontece em outros países, fazendo o contraponto com as grandes empresas privadas, para que haja o equilíbrio das forças de mercado e, consequentemente, melhores preços e maior renda para os produtores.

No território objeto de estudo, essas medidas poderiam ser um bom caminho para aumentar a produção interna, a produtividade, a eficiência produtiva e a capacidade de competitividade das indústrias cooperativas em relação às empresas não cooperativas, que estão presentes na cadeia produtiva do leite. Alguns entrevistados responderam que também é necessário estudar as melhores formas de realizar a negociação política e estratégica entre as cooperativas da região e entre essas e os setores públicos locais, sem que haja um desgaste nas relações de confiança entre elas.

Além disso, com o desenvolvimento da cadeia do leite nos assentamentos poderá haver uma maior inserção social de um grande contingente da população rural e urbana, da melhoria da qualidade de vida e do nível de desenvolvimento socioeconômico regional, que ainda é muito baixo na grande maioria dos municípios da região. Isso poderá ser feito através do fortalecimento das cooperativas de agricultores familiares regionais, da ampliação da participação social e da integração das políticas dos governos federal, estadual e municipal e do estímulo às práticas políticas de construção de um plano de desenvolvimento territorial-regional.

A cadeia do leite também poderá contribuir para promover a inclusão social de famílias que hoje fazem parte dos assentamentos da região, por meio da capacitação de recursos humanos para atuar na atividade produtiva, da geração de postos de trabalho e da geração de uma renda familiar líquida que poderá ultrapassar $\mathrm{R} \$ 1.500,00 /$ mês.

\section{PERFIL DAS COOPERATIVAS DOS ASSENTAMENTOS}

O crescimento recente da produção de leite na região de abrangência das cooperativas analisadas é muito significativo. Nos últimos anos, aumentou muito a produção de pequenos produtores familiares de assentamentos da região, na faixa de fronteira com o Uruguai, que vai desde o município de Herval, passando por Pedras Altas, Candiota, Hulha Negra e Bagé, até Santana do Livramento.

Verificou-se, também, que a redução da produção no inverno é muito mais acentuada nos assentamentos, devido principalmente ao baixo nível tecnológico, da genética 
e da disponibilidade de alimentação adequada para o gado. Enquanto a variação na produção e na captação das outras cooperativas e empresas privadas apresenta uma redução de $33 \%$ a $38 \%$, a queda na produção e no recebimento de leite no inverno nos assentamentos pode chegar a $80 \%$ em relação à produção do verão, caindo de 80.600 para 19.700 litros, entre essas duas estações (Quadro 1).

$\mathrm{Na}$ análise dessas cooperativas, verificou-se que, enquanto o grau de participação das cooperativas de assentados na produção total varia entre $38 \%$ (verão) e $18 \%$ (inverno), o número de produtores assentados que produzem leite corresponde a aproximadamente $70 \%$ do total dos produtores de leite da região de abrangência das cooperativas.

\begin{tabular}{|l|r|r|r|r|r|}
\hline \multicolumn{1}{|c|}{ Nome da Cooperativa } & \multicolumn{1}{c|}{$\begin{array}{c}\text { Cooperativa } \\
\text { verão }\end{array}$} & \multicolumn{1}{c|}{$\begin{array}{c}\text { Produtor } \\
\text { verão }\end{array}$} & $\begin{array}{c}\text { Cooperativa } \\
\text { inverno }\end{array}$ & $\begin{array}{c}\text { Produtor } \\
\text { inverno }\end{array}$ & $\begin{array}{c}\text { No de } \\
\text { associados }\end{array}$ \\
\hline TERRA NOVA (Canguçu) & 3.300 & 15,6 & 1.000 & 7,1 & 400 \\
\hline $\begin{array}{l}\text { COOPERFORTE } \\
\text { (Santana do Livramento) }\end{array}$ & 27.000 & 52,3 & 5.000 & 10,9 & 1.200 \\
\hline COOPERAL (Candiota) & 30.000 & 43,0 & 5.000 & 12,5 & 1.200 \\
\hline COOMAHER (Herval) & 3.300 & 47,6 & 1.700 & 27,8 & 75 \\
\hline COOPERVAL (Herval) & 5.000 & 28,0 & 2.300 & 18,0 & 200 \\
\hline $\begin{array}{l}\text { Associação de Pedras Altas } \\
\text { (assentamento) }\end{array}$ & 12.000 & 83,3 & 4.700 & 46,7 & 350 \\
\hline TOTAL (litros/dia) & $\mathbf{8 0 . 6 0 0}$ & --- & 19.700 & --- & $\mathbf{3 . 4 2 5}$ \\
\hline
\end{tabular}

Quadro 1: Produção e captação diária de leite das cooperativas analisadas - média por cooperativa e por produtor (litros/dia)

Fonte: Elaborado a partir de dados primários obtidos junto às cooperativas.

Os produtores associados da Cooperforte eram em torno de 400 famílias de assentados de 26 dos 35 assentamentos (de um total de quase 1.500 famílias) do município de Santana do Livramento e mais 50 famílias de pequenos agricultores de fora desses assentamentos. A cooperativa, em 2010, tinha uma capacidade de resfriamento de 3.500 litros, produz mais de 800 mil litros de leite/mês no verão, em torno de $60 \%$ da produção de leite do município de Santana do Livramento. A expectativa era de que até o final de o ano, o número de associados aumente para 550 famílias e que a capacidade de resfriamento aumente para 10 mil litros, resultado de financiamentos estatais a "fundo perdido". Com relação à produção do leite, constatou-se que a produtividade é muito baixa, ficando em torno de 4 a 8 litros/vaca/dia, principalmente devido ao baixo nível de tecnologia na produção, com vacas mestiças, que são preferidas devido a sua menor exigência (custos) em termos de alimentação. Todo o recolhimento do leite, até $25 \mathrm{~km}$, é realizado com três caminhões próprios, com capacidade para transportar até 28 mil litros, e com funcionários contratados diretamente.

Das 1.800 famílias de associados de outra cooperativa, a Cooperativa Regional dos Agricultores Assentados (COOPERAL), distribuídas nos quase 50 assentamentos entre Candiota e Hulha Negra, em torno de 700 famílias entregam leite para esta cooperativa. Atualmente, a produção no verão está ao redor de 900 mil litros/mês, e no inverno 
cai para 150 mil litros/mês, sendo $98 \%$ oriundos dos assentados (há alguns pequenos produtores não assentados).

Nessa cooperativa, na qual não há punição para os associados que fraudarem o leite, a produção de leite por produtor varia de 100 litros/mês a 1.500 litros/mês, predominantemente de vacas mestiças ou um misto de raças holandesas e Jérsei. Essa cooperativa também faz a entrega do leite para a Cosulat, recebe $5 \%$ do valor da produção para a sua manutenção e repassa a ração para os produtores a preço de custo. Os custos com o recolhimento do leite referem-se aos gastos com manutenção de caminhões (adquiridos com verbas públicas a "fundo perdido") e combustível, que representam mais de $\mathrm{R} \$ 12 \mathrm{mil} / \mathrm{mês}$, além dos salários de 8 motoristas que fazem o recolhimento durante 24 horas por dia. De acordo com seus dirigentes, a cooperativa necessita ainda de investimentos para a compra de mais um caminhão e de alguns resfriadores. A cooperativa perdeu, em relação ao ano passado, aproximadamente $30 \%$ dos seus produtores associados, que deixaram a cooperativa e passaram a fornecer leite diretamente para empresas não cooperativas do setor, principalmente devido ao melhor preço oferecido pela empresa no inverno.

A Cooperativa Terra Nova de Canguçu (Terra Nova) tem como associados os membros de 430 famílias de dezesseis assentamentos no município de Canguçu, que produzem milho, batata, feijão, mas apenas em torno de 200 eram ativos na entrega do leite. Além da produção de leite e mel, a cooperativa tem também, dentro dos assentamentos, um moinho para a produção de farinha de trigo e de milho e um descascador de arroz. A cooperativa recebe 100 mil litros de leite/mês no verão e em torno de 30 mil litros/mês no inverno. A produção de leite é realizada por uma média de 200 associados, que também utilizam baixa tecnologia, vacas mestiças (diversos cruzamentos) e das raças holandesa e Jérsei, com uma produtividade que varia de 2 a 5 litros/dia por vaca. Os principais gargalos da produção leiteira dessa cooperativa são relacionados à baixa qualidade genética do rebanho, à falta de assistência técnica e de investimentos na correção do solo, ao melhoramento das pastagens e em infraestrutura e a equipamentos para a ordenha e o resfriamento do leite.

De maneira geral, os dois principais problemas apontados pelos dirigentes das cooperativas de assentados da região eram os custos com recolhimento do leite e a perda de produtores associados para as empresas não cooperativas que atuam na região.

\section{CONSIDERAÇÕES FINAIS}

A partir do estudo realizado na região, foi possível observar a presença de alguns gargalos que poderão ser determinantes para o desenvolvimento dessas cooperativas e da região nos próximos anos. A tendência do setor leiteiro é que ocorra uma acelerada concentração na indústria de laticínios e que o cooperativismo, como já acontece em diversos países, passe a ter um papel mais importante nesse processo. Isso porque o controle da produção pelos produtores somente será possível com a presença de um cooperativismo forte, principalmente na etapa de captação do leite, pois essa representa um custo bastante significativo. 
Com base na opinião de alguns entrevistados, para que a formação de uma Central Regional de Leite seja bem sucedida na região e que seja garantido o fornecimento regular com qualidade e quantidade suficiente, é estratégico que haja a expansão da produção e da captação de leite em alguns municípios e assentamentos. Em função da existência de cooperativas locais, da existência prévia de capital social e da produção atual de leite e do seu potencial para aumentar a produção, a região, em um primeiro momento, poderia aproveitar a proximidade e a capacidade ociosa de mais de meio miIhão de litros/dia de uma planta industrial, de uma grande cooperativa, que tem como associados, predominantemente, produtores rurais não assentados, mas recebe praticamente toda a produção de leite dos assentamentos da região.

Para aumentar a produtividade, será necessário estruturar um sistema de fomento e assistência técnica, em uma escala que possa atender a todos os agricultores familiares associados das cooperativas. O principal objetivo é promover o acesso às tecnologias de produção adequadas para produzir leite com qualidade durante o ano inteiro, um aumento da produtividade média dos animais, o aumento da renda dos produtores $\mathrm{e}$ o desenvolvimento socioeconômico dessas famílias. Para melhorar e aumentar a produtividade e a produção leiteira, essas famílias deveriam receber orientação e capacitação sobre manejo sanitário do rebanho e da ordenha, qualidade do leite e melhor utilização da alimentação dos animais. Os fatores que podem assegurar um aumento da produtividade e da produção são: a qualidade da alimentação, o manejo correto e o melhoramento genético do rebanho.

Além de buscar a redução dos custos, é importante também ter como objetivo o aumento da produção, porque uma renda muito pequena para o produtor de leite limita os investimentos na atividade. Esse é um dos principais motivos para o fortalecimento das cooperativas de laticínios, integradas em redes ou em centrais, como já acontece em outros países, fazendo o contraponto com as grandes empresas privadas, para que haja o equilíbrio das forças de mercado e, consequentemente, melhores preços e maior renda para os produtores.

Complementarmente às demais medidas, o efetivo dinamismo da atividade produtiva do leite se dará com base, também, na melhoria do sistema de captação, estudando-se rotas, volumes, frequências e custos de transporte, a partir da melhor combinação de fatores, a estruturação da logística de suprimento, com vistas à redução de custos e ineficiências. Essas medidas seriam um bom caminho para aumentar a produção interna, a produtividade, a eficiência produtiva e a capacidade de competitividade das cooperativas em relação às empresas não cooperativas. É necessário também estudar as melhores formas de realizar a negociação política e estratégica entre as cooperativas da região e entre essas e os setores públicos locais, sem que haja um desgaste nas relações de confiança entre elas.

Algumas prefeituras dos pequenos e médios municípios da região deveriam aprofundar mais algumas experiências recentes em torno de iniciativas econômicas locais, construindo redes alternativas de comercialização de produtos locais, visando romper com redes de intermediários e incrementar atividades com potencial de dinamização econômica e distribuição de renda. Entre as atividades com grande potencial, surgiu a produção leiteira na região, podendo figurar como parte de uma estratégia de desen- 
volvimento territorial, através do capital social presente nas cooperativas de produção e de comercialização dos assentamentos. Apesar das limitações das administrações municipais, é possível a implementação de ações que rompam os circuitos fechados de acumulação e gerem emprego e renda.

A pesquisa revelou um potencial produtivo regional diversificado para a produção agropecuária e também espaço para diferentes formas de estruturação de parcerias entre as cooperativas. Com isso, fortaleceria a produção local, tendo como objetivo final o desenvolvimento da região, já que, em alguns municípios, a produção leiteira dessas cooperativas já é a sua principal fonte de renda, como é o caso de Pedras Altas, onde a produção leiteira dos assentamentos representa mais de $80 \%$ da renda total do município.

Nos assentamentos, já se verifica a organização interna da produção e o desenvolvimento do cooperativismo como a principal ferramenta de desenvolvimento socioeconômico dos assentamentos, principalmente na forma de Cooperativas de Produção Agropecuária (CPAs). Com isso, os assentados passaram a contar com unidades de beneficiamento da produção, administradas pelas cooperativas centrais e/ou regionais de comercialização e prestação de serviços, como as de coleta e processamento da produção de leite.

A melhoria das condições de vida ou benefícios socioeconômicos dos assentados, em consequência do aumento da competitividade no mercado, através da produção cooperativa, da incorporação das inovações tecnológicas, poderá contribuir positivamente para a solução de problemas de concentração da renda e da terra e do desemprego, assim como trazer resultados favoráveis aos movimentos sociais locais e ao esforço político da luta dos trabalhadores rurais sem terra.

Em uma segunda fase, pretende-se realizar uma análise reflexiva mais aprofundada, traçando-se alguns cenários internos e externos futuros e determinando-se ações estratégicas para o desenvolvimento da cadeia produtiva do leite nesses assentamentos.

\section{REFERÊNCIAS}

ABRAMOVAY, Ricardo. Funções e medidas da ruralidade no desenvolvimento contemporâneo. Texto para Discussão n. 702. Rio de Janeiro: IPEA, 2000.

BOISIER, Sergio E. Sociedad civil, participacion, conocimiento y gestion territorial. Santiago de Chile: ILPES, 1997.

CARVALHO, S. P. de et al. Reforma Agrária: a realidade de um assentamento rural. Campo e Território: revista de geografia agrária, v. 4, n. 8, p. 67-97, ago. 2009.

CEPEA-ESALQ/USP. Boletim do Leite. Ano 17, n. 194, fev./mar. 2011. Disponível em: <http://www.cepea.esalq.usp.br/leite/boletim/194.pdf>. Acesso em: 15 fev. 2010.

CORREA, C. A. Analyse Comparative de 9 Cas D'Agro-Industrie Rurale de L'Amerique Latine. Saint Quentin en Yvelines: Université de Versailles, 2004.

GUANZIROLI, Carlos (Coord.). Principais Fatores que Afetam o Desenvolvimento dos Assentamentos de Reforma Agrária no Brasil. Projeto de Cooperação Técnica - FAO/ INCRA. Brasília, 1998. Disponível em: <http://www.deser.org.br/pub_read.asp?id=67>. Acesso em: 15 fev. 2010. 
FEE - FUNDAÇÃO DE ECONOMIA E ESTATÍSTICA. Resumo Estatístico RS. Disponível em: <http://www.fee.tche.br/sitefee/pt/content/resumo/index.php>. Acesso em: 20 mar. 2011.

IBGE - INSTITUTO BRASILEIRO DE GEOGRAFIA E ESTATÍSTICA. Cidades. Disponível em: <http://www.ibge.gov.br/cidadesat/topwindow.htm>. Acesso em: 20 mar. 2011.

LEITE, Sérgio; HEREDIA, Beatriz; MEDEIROS, L. S. Impactos dos assentamentos: um estudo sobre o meio rural brasileiro. São Paulo: UNESP/NEAD/INCRA/MDA, 2004.

MORAES, J. L. A. Dinâmicas Sócio-Econômicas de Desenvolvimento dos Territórios Rurais: Os Sistemas Produtivos Localizados (SPLS) da Região Vale do Rio Pardo-RS. Tese (Doutorado - Programa de Pós-Graduação em Desenvolvimento Rural - PGDR) Universidade Federal do Rio Grande do Sul, Porto Alegre, 2008.

NAVARRO, Zander. Desenvolvimento Rural no Brasil: os limites do passado e os caminhos do futuro. Revista Estudos Avançados, v. 16, n. 43. São Paulo: USP, 2001.

POLANYI, Karl. A Grande Transformação: as origens da nossa época. 8. ed. Rio de Janeiro: Campus, 2000.

RAFFESTIN, Claude. Por uma Geografia do Poder. São Paulo: Ática, 1993.

REIS, José. Uma Epistemologia do Território. Lisboa: Instituto Superior de Economia e Gestão; Universidade Técnica de Lisboa 2006.

REQUIER-DESJARDINS, Denis. Multifonctionnalité, territoire et secteur agro alimentaire: une approche par les "systèmes agroalimentaires localisés". CAHIERS DU C3ED, n. 2-2001: jun., 2002. Saint Quentin en Yvelines: Université de Versailles: 2002.

SABOURIN, Eric. Desenvolvimento territorial e abordagem territorial - conceitos, estratégias e atores. In: Sabourin, E.; TEIXEIRA, O. A. (Eds.). Planejamento e desenvolvimento dos territórios rurais - conceitos, controvérsias, experiências. Brasília: Embrapa Informação Tecnológica, 2002. p. 21-37.

SCHEJTMAN, A.; BERDEGUÉ, J. Desarrollo Territorial Rural. Santiago: RIMISP, 2003. 